\title{
Do Gestational Obesity and Gestational Diabetes Have an Independent Effect on Neonatal Adiposity? Results of Mediation Analysis from a Cohort Study in South India
}

\author{
This article was published in the following Dove Press journal: \\ Clinical Epidemiology
}

\begin{abstract}
Giridhara R Babu, (D) ${ }^{\prime} \mathrm{R}$ Deepa, (D)' Melissa Glenda Lewis, ${ }^{2}$ Eunice Lobo, (D) Anjaly Krishnan, (iD)' Yamuna Ana, iD Jodie G Katon, ${ }^{3,4}$ Daniel A Enquobahrie, ${ }^{5}$ Onyebuchi A Arah, (iD ${ }^{6-8}$ Sanjay Kinra, ${ }^{9}$ GVS Murthy iD 2,10

IIndian Institute of Public Health-Bangalore, Public Health Foundation of India (PHFI), Bangalore, India; ${ }^{2}$ Indian Institute of Public Health-Hyderabad, Public Health Foundation of India (PHFI), Hyderabad, India; ${ }^{3}$ Health Services Research and Development Center of Innovation for Veteran-Centered and Value-Driven Care, VA Puget Sound Health Care System, Seattle, WA, USA; ${ }^{4}$ Department of Health Services, University of Washington, Seattle, WA, USA;

${ }^{5}$ Department of Epidemiology, School of Public Health, University of Washington, Seattle, WA, USA; ${ }^{6}$ Department of Epidemiology, Fielding School of Public Health, University of California, Los Angeles (UCLA), Los Angeles, CA, USA; ${ }^{7}$ California Center for Population Research, University of California, Los Angeles (UCLA), Los Angeles, CA, USA; ${ }^{8}$ UCLA Center for Health Policy Research, Los Angeles, CA, USA; ${ }^{9}$ Non-communicable Disease Epidemiology, London School of Hygiene \& Tropical Medicine and, University College London Hospital, London, UK;

${ }^{10}$ International Centre for Eye Health,

Department of Clinical Research, London

School of Hygiene \& Tropical Medicine,

London, UK
\end{abstract}

Correspondence: Giridhara R Babu Indian Institute of Public Health-

Bangalore, Public Health Foundation of India (PHFI), Bangalore, India, Besides

Leprosy Hospital, I st Cross, Magadi Road,

Bangalore 560023, India

Email giridhar@iiphh.org
Purpose: Neonates born to mothers with obesity or gestational diabetes mellitus (GDM) have an increased chance of various metabolic disorders later in life. In India, it is unclear whether maternal obesity or GDM is related to offspring adiposity. We aimed to understand the independent effect of maternal obesity and GDM with neonatal adiposity and whether GDM has a mediating effect between maternal obesity and neonatal adiposity.

Methods: We recruited a cohort of 1120 women (between April 2016 and February 2019) from the public hospitals in Bangalore, India, who voluntarily agreed to participate and provided written informed consent. The primary outcome was neonatal adiposity, defined as the sum of skinfold thickness $>85^{\text {th }}$ percentile. Exposure included maternal obesity, defined as $>90^{\text {th }}$ percentile of skinfold thickness. GDM, the potential mediator, was classified using the World Health Organization criteria by oral glucose tolerance test. Binary logistic regression was applied to test the effect of maternal obesity and GDM on neonatal adiposity, adjusting for potential confounders. We used Paramed command in STATA version 14 for analyzing mediating effects.

Results: We found that maternal obesity (odds ratio $(\mathrm{OR})=2.16,95 \%$ CI $1.46,3.18$ ) and GDM (OR=2.21, 95\% CI1.38, 3.52) have an independent effect on neonatal adiposity. GDM significantly mediates $25.2 \%$ of the total effect between maternal obesity and neonatal adiposity, (natural direct effect $\mathrm{OR}=1.1695 \%$ CI 1.04, 1.30) with significant direct effect of maternal obesity (natural direct effect $\mathrm{OR}=1.9095 \% \mathrm{CI} 1.16,3.10$ ) and significant total effect (OR=2.20 95\% CI 1.35, 3.58).

Conclusion: We showed that maternal obesity and GDM are independently associated with offspring adiposity. Also, GDM mediates the association of maternal obesity on adiposity in children. Interventions focused on obesity prevention in women, and effective screening and management of GDM may contribute to reducing childhood obesity in India.

Keywords: mediation effects, skinfold thickness, GDM, obesity in pregnancy, childhood obesity

\section{Introduction}

Obesity in pregnancy is a significant public health concern as it increases the risk of several complications during pregnancy and the perinatal period. ${ }^{1,2}$ Nearly 4.3 million pregnant women are overweight or obese in India, reflecting the high prevalence of overweight and obesity in low-middle income countries (LMICs). ${ }^{3,4}$ Also, it is known that children are twice as likely to have obesity 
if their mothers were obese during the first trimester of pregnancy. ${ }^{5}$ Maternal obesity results in fetal macrosomia. ${ }^{6-10}$ Also, obesity during pregnancy significantly predisposes pregnant women to develop Gestational diabetes mellitus (GDM), defined as hyperglycaemia that first develops during pregnancy or first diagnosed during pregnancy. Several mechanisms suggest higher risk of developing GDM in obese women. These include higher insulin resistance in obese women compared to women of healthy weight, leading to the increased availability of lipids for fetal growth and development. ${ }^{11,12}$ GDM affects more than 17.8 million women worldwide, among whom $28 \%$ are in India. ${ }^{13}$

Maternal obesity and Gestational diabetes mellitus (GDM) are associated with several adverse effects in mothers as well as children during pregnancy and beyond. These include higher cesarean section rate, preterm delivery, fetal macrosomia, and fetal death. ${ }^{6,14-20}$ A recent meta-analysis found that obesity during pregnancy increases the risk of fetal adiposity, with risk rising across the overweight and obese categories proportionately. ${ }^{21}$ Moreover, GDM results in several adverse fetal implications. Babies of women with GDM are prone to develop adiposity, characterized by substantial fat deposition in most skin folds in all areas of the body. ${ }^{22}$ Adult-onset obesity and related complications such as hypertension, Type 2 diabetes mellitus, Cardiovascular Diseases (CVDs) more likely affect children with adiposity. ${ }^{23}$ Several factors, including maternal obesity and GDM, are linked to the increasing burden of fetal adiposity. ${ }^{6,24,25}$ Evidence suggests that obesity during pregnancy is a stronger determinant of fetal adiposity compared to pre-pregnancy BMI. ${ }^{11}$

Hitherto, the role of maternal obesity and GDM in resulting fetal adiposity is mostly studied in high-income countries. ${ }^{26,27}$ Understanding the putative causal path of maternal obesity and fetal adiposity, including the mediation role of GDM is essential to prioritize policy planning and implementation for limiting the adverse effects of these conditions. ${ }^{28}$ In the Indian context, it is unclear as to what degree of maternal obesity and GDM contribute, and whether they are related to each other in resulting adiposity in children. Since two-thirds of pregnant women in India use the public hospitals for the antenatal care services, ${ }^{29}$ we aimed to understand the extent of association of maternal obesity with adiposity in neonates, and the mediating role of this association by GDM using a cohort study of women of public hospitals in India.

\section{Materials and Methods}

Study Sample, Data Collection, and Ethics Consideration

We established a pregnancy cohort in April 2016, titled as the "Maternal Antecedents of Adiposity Studying the Transgenerational role of Hyperglycemia and Insulin" (MAASTHI). We have published a detailed protocol earlier. ${ }^{30}$ In brief, we approached women in the waiting area of public hospitals and explained the study in detail and included them if they voluntarily agreed to participate and provided written informed consent. We included pregnant women aged above 18 years, in their second trimester (within 36 gestational weeks) visiting and planning to deliver in three public hospitals with their residence in the nearby study area. We excluded participants with severe, past, or current illness or their inability to complete the oral glucose tolerance test (OGTT) before 36 weeks of gestation.

After obtaining written informed consent, our trained research staff recruited eligible pregnant women and conducted face-to-face interviews by ensuring privacy and confidentiality. Interview details included sociodemographic information, use of tobacco and alcohol, family history of diabetes and cardiovascular diseases (CVD), obstetric history, and assessment of psychosocial environment using a validated version of the Edinburgh Postnatal Depression Scale (EPDS), and social support scale. We measured the physical activity of pregnant mothers using a validated Physical Activity Level (PAL) questionnaire. $^{31}$ The questionnaire had five domains: exercise, hobbies, household chores, sedentary activities, and other common daily activities. These domains include all the activities performed by women in an urban setting. Metabolic Equivalent (MET) values of each activity were then calculated by multiplying three components, namely MET allotted value, duration of activity done, and frequency done in a week. The combined MET value was calculated by adding MET values of individual physical activity. Categorization of the combined score was done, and the level of physical activity was defined as "low" if it was $<600$ METs, "moderate" when 600-2999 METs, and as "high" when it is $\geq 3000$ METs.

For the current analyses, we used data from April 2016 to February 2019. Research assistants entered all data in a validated application on an Android device.

The study protocol was reviewed and approved by the Institutional Ethics Committee of the Indian Institute of 
Public Health, Bangalore campus (IEC no: IIPHHB/ TRCIEC/091/2015; dated 13/11/2015). The study was conducted in accordance with the Declaration of Helsinki.

\section{Exposure Assessment - Maternal Obesity} Maternal height, weight, and the sum of skinfold thickness (SFT) measurement at three sites (biceps, triceps, and subscapular) was measured during the hospital visit of the participant using a calibrated portable stadiometer (SECA 213), digital weighing scale (Tanita), and Holtain Calipers (Holtain, UK) respectively. Two readings for weight and height and three readings for skinfold thickness measurements were taken. Women were considered obese - if the sum of skinfold thickness was higher than the $90^{\text {th }}$ percentile of the distribution of the sum of skinfold thickness in the study sample. Research assistants were trained and certified in anthropometry at the beginning of the study and then annually to obtain accurate measurements and to avoid inter- and intra-observer variation. All anthropometric equipment were calibrated and validated every month using standardized weights and scales.

\section{GDM Diagnosis}

Between 24 to 36 weeks of gestation, we invited the participants to undergo a $2 \mathrm{hr} 75$ grams oral glucose tolerance test (OGTT) after overnight fasting for at least eight hours. ${ }^{32} \mathrm{We}$ collected $2 \mathrm{~mL}$ blood in fasting and $2 \mathrm{hr}$ postprandial for glucose analysis. We followed the WHO diagnostic criteria developed by the International Association of Diabetes and Pregnancy Study Group (IADPSG) for the classification of gestational diabetes mellitus (GDM). Accordingly, GDM was diagnosed if the fasting blood sugar (FBS) was equal to or more than $92 \mathrm{mg} / \mathrm{dL}$, and $2 \mathrm{hr}$ postprandial blood sugar (PPBS) equal to or more than $153 \mathrm{mg} / \mathrm{dL}^{33}$

\section{Neonatal Adiposity}

We collected details at birth through structured interviews and anthropometric measurements within seven days of the birth of the child. Anthropometric measurements included weight, length, crown-rump length (CRL), circumferences - head, chest, waist, hip, middleupper arm (MUAC), and skinfold thickness. We weighed the neonates on the calibrated digital weighing scale (SECA 354), with two readings taken to the nearest $0.5 \mathrm{~g}$. We measured crown-heel and crown-rump length using SECA 417 infantometer to the nearest $0.1 \mathrm{~cm}$. We used the Chasmors body circumference tape to measure circumferences, with two readings taken to the nearest $0.1 \mathrm{~cm}$. We measured the skinfold thickness in neonates using Holtain Calipers (Holtain, UK) at three sites, namely biceps, triceps, and subscapular areas. The sum of skinfold thickness was calculated (SFT), and centile charts for the sum were determined. A neonate was classified as having excessive fat deposition (adiposity) if SFT was above the $85^{\text {th }}$ percentile for the neonate's gestational age. Indian standard for classification of neonates based on the sex and order of the birth was used for the weight for gestational age. ${ }^{34}$ The primary information regarding gestational age, parity, and sex from the cohort were used to derive the variable, weight for gestational age. Hence a neonate weighing less than the $10^{\text {th }}$ percentile was classified as small for gestational age (SGA), between 10 to $90^{\text {th }}$ percentile was appropriate for gestational age (AGA) or healthy, and higher than $90^{\text {th }}$ percentile was large for gestational age (LGA). ${ }^{34}$

\section{Confounders}

Confounders were selected based on literature review and included a priori in the analyses. Studies have shown that GDM significantly and progressively increases due to increased age; the other confounders include parity and family history of diabetes. ${ }^{35}$ We also adjusted for maternal obesity as measured through the sum of skinfold thickness measured during pregnancy, as they are closely correlated. $^{36,37}$ Maternal height is an independent risk factor for GDM. ${ }^{37,38}$ The religion of the respondent, husband's income, and alcohol intake were also adjusted. ${ }^{39}$ We also adjusted for physical activity (MET values), as increased physical activity is associated with decreased neonatal adiposity, ${ }^{40}$ and reduced rates of GDM. ${ }^{41}$

\section{Statistical Analysis}

Power analysis was performed for testing mediation effect in multiple logistic regression by a method proposed by Vittinghoff, Sen, and McCulloch's using the "R" package. ${ }^{42}$ The power of the study was $99 \%$ considering $\mathrm{n}=1120$, the regression coefficient of GDM (after adjusting for confounders) $=1.99$, the standard deviation of GDM $=$ 0.370 , the prevalence of neonatal obesity $=0.146$, multiple correlations of GDM with the confounders and neonatal obesity $=0.048$ and level of significance $=0.05$.

We cleaned and organized the data ahead of performing analysis using STATA version 14. A total of 1120 observations were considered for the analysis, of which 1091 were included for SFT analysis. Missing data were analyzed using available case analysis. Categorical variables were expressed 
as frequency (f) and percentages (\%) and normally distributed as mean and standard deviation. Association between various socio-demographic factors to GDM, Obesity, SFT, and weight for gestational age were assessed using the Chisquare test and Fisher's exact test when appropriate.

We used univariate logistic regression to test the independent effect of maternal obesity and GDM on neonatal adiposity. Homogeneity of odds ratio (Breslow-Day test) across the levels of GDM and test of conditional independence was assessed using the Mantel Haenszel test. Multiple logistic regression was adopted to adjust for potential confounders. We evaluated multicollinearity among the confounders using a correlation matrix; no multicollinearity if the correlation was less than 0.90 . Multicollinearity between exposure and mediator was assessed using the variance inflation factor (VIF) using linear regression, as suggested by Midi $\mathrm{H}$ for logistic regression models. ${ }^{43}$

Four separate models were performed and compared using different model diagnostics (Likelihood value, Hosmer \& Lemeshow test of the goodness of fit, Nagelkerke R Square, and classification accuracy). Model 1 shows the association of maternal obesity on neonatal adiposity adjusting for confounders. Model 2 shows the association of GDM on neonatal adiposity adjusting for confounders. Model 3 shows the association of maternal obesity, GDM on neonatal adiposity adjusting for confounders (with interaction). Model 4 shows the association of maternal obesity, GDM on neonatal adiposity adjusting for confounders (without interaction). We report the odds ratio (OR) with $95 \%$ confidence interval (CI) and $\mathrm{p}$ values.

The natural direct, natural indirect (mediated by GDM), and the marginal total effects were estimated using mediation analysis using the Logit model. We performed a bootstrapping analysis with 1000 replications. The direct effect= the effect of GDM on the neonatal adiposity without the effect of GDM, and indirect effect= the effect of GDM on the neonatal adiposity mediated via GDM. The product of direct and indirect effects are expressed as the total effect. We estimated the proportion mediated, ${ }^{44}$ using Paramed command, ${ }^{45}$ as per the approach suggested by Baron and Kenny. ${ }^{46}$

Logit $\{\mathrm{P}($ neonatal adiposity $=1 \mid$ maternal obesity, neonatal adiposity, confounders $)\}=(\beta 0+\beta 1$ maternal obesity $+\beta 2 \mathrm{GDM})+\beta 3$ confounders $\}$
Logit $\{\mathrm{P}(\mathrm{GDM}=1 \mid$ maternal obesity, confounders $)\}=\lambda$ $+\lambda 1$ maternal obesity $+\lambda 3$ confounders $\}$

\section{Results}

The characteristics of women $(\mathrm{N}=1020)$ and neonates enrolled in the MAASTHI cohort from 2016 to 2019 based on neonatal adiposity and large for gestational age (LGA) are presented in Table 1. Among the neonates born during the cohort, $14.6 \%$ had SFT $>85$ th percentile and were large for gestational age $(n=163 / 1120)$. Almost all children born in the group were reportedly healthy during assessment after birth. We found that less than $3.6 \%$ reported aspiration of babies while resuscitation was reported in $42 \%$ obese babies and $23.6 \%$ of babies with LGA. Additionally, $4.3 \%$ of neonates with adiposity did not cry soon after delivery compared to less than $2 \%$ LGA neonates (Table 1).

The characteristics of pregnant women and neonates based on maternal GDM and obesity status are provided in Table 2. Out of the total participants, 9.7\% of the mothers were obese, and 16.4\% were diagnosed with GDM. We found that $62.4 \%(n=109)$ obese and $52.2 \%(n=184)$ with GDM were Muslims. In our study sample, approximately seven out of 10 women with obesity $(70.7 \%)$ and nearly two-thirds of women with GDM (63.5\%) were multiparous. Infertility was reported in women with GDM as well as among women with obesity. Some form of resuscitation was reported in $34.9 \%$ of babies born to women with obesity, and $36 \%$ of babies born to GDM mothers (Table 2).

As seen in Table 3, women with obesity delivered a higher proportion of babies with large birth weight than mothers without obesity $(18.3 \%$ vs $9.1 \%)$. Similarly, women with GDM also delivered a higher proportion of babies with large birth weight compared to non-GDM women (18.5\% vs $8.3 \%)$. Further, compared to women without obesity, babies born to women with obesity had higher head (8.9\% vs $12.8 \%)$, chest $(8.3 \%$ vs $12.8 \%)$, and middle-upper arm circumference $(9.0 \%$ vs $18.3 \%)$; similarly women with GDM delivered higher proportion of babies with larger MUAC than non-GDM mothers $(16.8 \%$ vs $8.3 \%)$. The percentage of babies with adiposity $(>85$ th percentile of the sum of skinfold thickness) was higher among women with obesity (25.7\% vs $13.5 \%)$ and women with GDM $(23.9 \%$ vs $12.7 \%)$ when compared to their respective control groups. (Table 3) 
Table I Descriptive Statistics of Maternal and Neonatal Characteristics in Relation to Neonatal Adiposity and Large for Gestational Age (LGA) in MAASTHI Cohort 2016-19, India

\begin{tabular}{|c|c|c|c|c|c|c|c|}
\hline \multirow[t]{3}{*}{ Characteristics } & \multirow[t]{3}{*}{ Categories } & \multicolumn{3}{|c|}{ Sum of Skinfold Thickness } & \multicolumn{3}{|c|}{ Weight for Gestational Age } \\
\hline & & $\begin{array}{l}\leq 85 \text { th } \\
\text { Percentile } \\
(n=957)\end{array}$ & $\begin{array}{l}>85 \text { th } \\
\text { Percentile } \\
(n=163)\end{array}$ & p value & $\begin{array}{l}\leq 90 \text { th } \\
\text { Percentile } \\
(n=957)\end{array}$ & $\begin{array}{l}>90 \text { th } \\
\text { Percentile } \\
(n=163)\end{array}$ & $\mathrm{p}$ value \\
\hline & & $f(\%)$ & $f(\%)$ & & $f(\%)$ & $f(\%)$ & \\
\hline \multicolumn{2}{|l|}{ Maternal Age ${ }^{a}$} & $24.24 \pm 4.03$ & $24.25 \pm 4.03$ & 0.96 & $24.12 \pm 3.99$ & $25.94 \pm 4.22$ & 0.02 \\
\hline \multirow[t]{3}{*}{ Religion } & Hinduism & $458(48 \%)$ & $78(47.9 \%)$ & \multirow[t]{3}{*}{0.79} & $427(46.4 \%)$ & $24(43.6 \%)$ & \multirow[t]{3}{*}{0.08} \\
\hline & Christianity & $3 I(3.2 \%)$ & $7(4.3 \%)$ & & $30(3.3 \%)$ & $5(9.1 \%)$ & \\
\hline & Islam & $466(48.8 \%)$ & $78(47.9 \%)$ & & $463(50.3 \%)$ & $26(47.3 \%)$ & \\
\hline \multirow[t]{2}{*}{ Participant's Education } & $\begin{array}{l}\text { Primary school } \\
\text { and below }\end{array}$ & $68(7.1 \%)$ & $\mathrm{II}(6.7 \%)$ & \multirow[t]{2}{*}{0.86} & $68(7.4 \%)$ & $3(5.5 \%)$ & \multirow[t]{2}{*}{0.59} \\
\hline & $\begin{array}{l}\text { Middle school } \\
\text { and above }\end{array}$ & $887(92.9 \%)$ & $152(93.3 \%)$ & & $852(92.6 \%)$ & $52(94.5 \%)$ & \\
\hline \multirow[t]{2}{*}{ Husband's Education } & $\begin{array}{l}\text { Primary school } \\
\text { and below }\end{array}$ & $182(19.1 \%)$ & $37(22.7 \%)$ & \multirow[t]{2}{*}{0.28} & $184(20 \%)$ & $\mathrm{II}(20.0 \%)$ & \multirow[t]{2}{*}{1.000} \\
\hline & $\begin{array}{l}\text { Middle school } \\
\text { and above }\end{array}$ & $773(80.9 \%)$ & $126(77.3 \%)$ & & $736(80.0 \%)$ & $44(80.0 \%)$ & \\
\hline \multirow{3}{*}{$\begin{array}{l}\text { Participant's current } \\
\text { occupation }\end{array}$} & Unemployed & $894(93.4 \%)$ & $147(90.2 \%)$ & \multirow[t]{3}{*}{0.17} & $862(93.7 \%)$ & $51(92.7 \%)$ & \multirow[t]{3}{*}{$0.81^{\#}$} \\
\hline & $\begin{array}{l}\text { Unskilled } \\
\text { worker }\end{array}$ & $44(4.6 \%)$ & $9(5.5 \%)$ & & $39(4.2 \%)$ & $3(5.5 \%)$ & \\
\hline & Skilled workers & $19(2.0 \%)$ & $7(4.3 \%)$ & & $19(2.1 \%)$ & $\mathrm{I}(\mathrm{I} .8 \%)$ & \\
\hline \multirow[t]{2}{*}{ Parity } & Nulliparous & $417(43.6 \%)$ & $65(39.9 \%)$ & \multirow[t]{2}{*}{0.37} & $414(45.0 \%)$ & $24(43.6 \%)$ & \multirow[t]{2}{*}{0.84} \\
\hline & Multiparous & $539(56.4 \%)$ & $98(60.1 \%)$ & & $506(55.0 \%)$ & $31(56.4 \%)$ & \\
\hline \multirow[t]{3}{*}{ Family history of diabetes } & None & $748(78.4 \%)$ & $123(75.5 \%)$ & \multirow[t]{3}{*}{0.38} & $718(78.3 \%)$ & $4 I(74.5 \%)$ & \multirow[t]{3}{*}{0.78} \\
\hline & One parent & $182(19.1 \%)$ & $33(20.2 \%)$ & & $175(19.1 \%)$ & $12(21.8 \%)$ & \\
\hline & Both parent & $24(2.5 \%)$ & $7(4.3 \%)$ & & $24(2.6 \%)$ & $2(3.6 \%)$ & \\
\hline Participant's history of GDM & Yes & $10(1.0 \%)$ & $3(1.8 \%)$ & $0.42^{\#}$ & $10(1.1 \%)$ & $\mathrm{I}(\mathrm{I} .8 \%)$ & $0.47^{\#}$ \\
\hline $\begin{array}{l}\text { Participant's history of } \\
\text { Hypertension }\end{array}$ & Yes & $13(1.4 \%)$ & $2(1.2 \%)$ & $1.000^{\#}$ & $14(1.5 \%)$ & 0 & $1.000^{\#}$ \\
\hline $\begin{array}{l}\text { Participant's history of } \\
\text { Anaemia }\end{array}$ & Yes & $418(43.8 \%)$ & $67(41.1 \%)$ & 0.53 & $394(42.9 \%)$ & $25(45.5 \%)$ & 0.71 \\
\hline $\begin{array}{l}\text { Current GDM status during } \\
\text { assessment }\end{array}$ & Yes & $140(\mid 4.6 \%)$ & $44(27.0 \%)$ & $<0.001$ & $148(16.1 \%)$ & $20(36.4 \%)$ & $<0.001$ \\
\hline $\begin{array}{l}\text { Current Hypertension status } \\
\text { during the assessment }\end{array}$ & Yes & $4 \mathrm{I}(4.4 \%)$ & $14(9.2 \%)$ & 0.01 & $47(5.3 \%)$ & $4(7.4 \%)$ & $0.53^{\#}$ \\
\hline Participant's obesity status & Yes & $8 \mathrm{I}(8.7 \%)$ & $28(17.4 \%)$ & 0.001 & $91(10.1 \%)$ & $10(18.9 \%)$ & 0.05 \\
\hline $\begin{array}{l}\text { Husband's alcohol } \\
\text { consumption }\end{array}$ & Yes & $130(13.8 \%)$ & $28(17.5 \%)$ & 0.208 & $119(13.1 \%)$ & $9(16.4 \%)$ & 0.5 \\
\hline
\end{tabular}


Table I (Continued).

\begin{tabular}{|c|c|c|c|c|c|c|c|}
\hline \multirow[t]{3}{*}{ Characteristics } & \multirow[t]{3}{*}{ Categories } & \multicolumn{3}{|c|}{ Sum of Skinfold Thickness } & \multicolumn{3}{|c|}{ Weight for Gestational Age } \\
\hline & & $\begin{array}{l}\leq 85 \text { th } \\
\text { Percentile } \\
(n=957)\end{array}$ & $\begin{array}{l}>85 \text { th } \\
\text { Percentile } \\
(n=163)\end{array}$ & p value & $\begin{array}{l}\leq 90 \text { th } \\
\text { Percentile } \\
(n=957)\end{array}$ & $\begin{array}{l}>90 \text { th } \\
\text { Percentile } \\
(n=163)\end{array}$ & $\mathrm{p}$ value \\
\hline & & $f(\%)$ & $f(\%)$ & & $f(\%)$ & $f(\%)$ & \\
\hline \multirow[t]{4}{*}{ Delivery type } & $\begin{array}{l}\text { Spontaneous } \\
\text { vaginal delivery }\end{array}$ & $506(52.9 \%)$ & $79(48.5 \%)$ & \multirow[t]{4}{*}{$0.54^{\#}$} & $484(52.6 \%)$ & $23(41.8 \%)$ & \multirow[t]{4}{*}{$0.34^{\#}$} \\
\hline & $\begin{array}{l}\text { Emergency } \\
\text { caesarean }\end{array}$ & $270(28.2 \%)$ & $55(33.7 \%)$ & & $270(29.3 \%)$ & $21(38.2 \%)$ & \\
\hline & $\begin{array}{l}\text { Elective } \\
\text { caesarean }\end{array}$ & $179(\mid 8.7 \%)$ & $29(17.8 \%)$ & & $164(17.8 \%)$ & $\mathrm{II}(2 \%)$ & \\
\hline & $\begin{array}{l}\text { Outlet forceps } \\
\text { delivery }\end{array}$ & $2(0.2 \%)$ & 0 & & $2(0.2 \%)$ & 0 & \\
\hline \multirow[t]{2}{*}{ Health status of the mother } & Healthy & $818(85.5 \%)$ & $136(83.4 \%)$ & \multirow[t]{2}{*}{0.5} & $784(85.2 \%)$ & $46(83.6 \%)$ & \multirow[t]{2}{*}{0.75} \\
\hline & Illness present & $139(\mid 4.5 \%)$ & $27(16.6 \%)$ & & $136(14.8 \%)$ & $9(16.4 \%)$ & \\
\hline \multirow[t]{2}{*}{ Health status of the baby } & Healthy & $950(99.3 \%)$ & $161(98.8 \%)$ & \multirow[t]{2}{*}{$0.63^{\#}$} & $914(99.3 \%)$ & $55(100 \%)$ & \multirow[t]{2}{*}{$1.000^{\#}$} \\
\hline & Diseased & $7(0.7 \%)$ & $2(1.2 \%)$ & & $6(0.7 \%)$ & 0 & \\
\hline \multirow[t]{2}{*}{ Sex } & Male & $480(50.2 \%)$ & $87(53.4 \%)$ & \multirow[t]{2}{*}{0.45} & $455(49.5 \%)$ & $31(56.4 \%)$ & \multirow[t]{2}{*}{0.32} \\
\hline & Female & $477(49.8 \%)$ & $76(46.6 \%)$ & & $465(50.5 \%)$ & $24(43.6 \%)$ & \\
\hline $\begin{array}{l}\text { Baby cried soon after } \\
\text { delivery }\end{array}$ & Yes & $938(98.0 \%)$ & $156(95.7 \%)$ & $0.09^{\#}$ & $900(97.8 \%)$ & $54(98.2 \%)$ & $1.000^{\#}$ \\
\hline Aspiration & Yes & $23(2.4 \%)$ & $3(1.8 \%)$ & $1.000^{\#}$ & $19(2.1 \%)$ & $2(3.6 \%)$ & $0.33^{\#}$ \\
\hline Resuscitation & Yes & $32 \mathrm{I}(34.2 \%)$ & $47(42.0 \%)$ & 0.013 & $309(33.6 \%)$ & $13(23.6 \%)$ & 0.13 \\
\hline
\end{tabular}

Notes: ${ }^{a}$ Mean \pm standard deviation is mentioned instead of frequency and percentage with an independent sample $t$-test, $\mathrm{p}$-value. ${ }^{\#}$ Fishers exact test $\mathrm{p}$-value. Bold indicates statistical significance at $5 \%$.

\section{Independent Effect}

Univariate logistic regression was performed to determine the independent effects of GDM and maternal obesity with neonatal adiposity. We found that both GDM and maternal obesity have an independent impact on neonatal adiposity, maternal obesity $\mathrm{OR}=2.16$ (95\% CI 1.46, 3.18), and GDM $\mathrm{OR}=2.21(95 \% \mathrm{CI} 1.38,3.52)$ respectively (Table 4$)$. The homogeneity of odds ratio across the levels of GDM using the Breslow-Day test was insignificant $(\chi 2=0.14$, $p$-value $=0.71$ ), indicating that the association between GDM and neonatal adiposity did not differ significantly between women with and without GDM. The test of conditional independence using Mantel Haenszel indicated that maternal obesity and neonatal adiposity are conditionally independent, given the status of maternal obesity ( $\mathrm{p}$-value $=0.008$ ) and also vice versa $(p$-value $=0.002)($ data not present in the table $)$.

\section{Adjusted Effect}

The results of the multiple Binary logistic regressions for four models are also shown in Table 4. Due to multicollinearity among gravida and parity, we performed separate multiple regression models to choose the best model. Based on the Likelihood ratio test, parity was better than gravida in model fitting. The final model included GDM, maternal obesity, religion, MET values, participant's history of diabetes, parity, family history of diabetes, husband's alcohol consumption status, maternal age, husband's income, and participant's height. Four separate models were performed and compared using different model diagnostics. We observed no significant multiplicative interaction between maternal obesity and GDM ( $p$ value $=0.78$ ). The likelihood value, Hosmer $\&$ Lemeshow test of the goodness of fit, Nagelkerke R Square, and 
Table 2 Descriptive Statistics of Maternal and Neonatal Characteristics in Relation to Maternal Obesity and Gestational Diabetes Mellitus (GDM) in MAASTHI Cohort 2016-19, India

\begin{tabular}{|c|c|c|c|c|c|c|c|}
\hline \multicolumn{2}{|l|}{ Characteristics } & \multicolumn{3}{|c|}{ Maternal Obesity Status ${ }^{b}$} & \multicolumn{3}{|c|}{ GDM Status $^{c}$} \\
\hline & & \multirow{2}{*}{$\begin{array}{l}\text { Yes } \\
(n=109)\end{array}$} & \multirow{2}{*}{$\begin{array}{l}\begin{array}{l}\text { No } \\
(n=982)\end{array} \\
f(\%)\end{array}$} & \multirow[t]{2}{*}{$\mathrm{p}$ value } & \multirow{2}{*}{$\begin{array}{l}\begin{array}{l}\text { Yes } \\
(n=\mid 84)\end{array} \\
f(\%)\end{array}$} & \multirow{2}{*}{$\begin{array}{l}\begin{array}{l}\text { No } \\
(n=936)\end{array} \\
f(\%)\end{array}$} & \multirow[t]{2}{*}{$\mathrm{p}$ value } \\
\hline & & & & & & & \\
\hline Maternal Age ${ }^{a}$ & & $25.14 \pm 4.23$ & $24.16 \pm 4.0$ & 0.02 & $25.37 \pm 4.25$ & $24.01 \pm 3.95$ & $<0.001$ \\
\hline \multirow[t]{3}{*}{ Religion } & Hinduism & $37(33.9 \%)$ & $482(49.1 \%)$ & \multirow[t]{3}{*}{0.01} & $83(45.1 \%)$ & $453(48.5 \%)$ & \multirow[t]{3}{*}{0.54} \\
\hline & Christianity & $4(3.7 \%)$ & $34(3.5 \%)$ & & $5(2.7 \%)$ & $33(3.5 \%)$ & \\
\hline & Islam & $68(62.4 \%)$ & $466(47.5 \%)$ & & $96(52.2 \%)$ & $448(48.0 \%)$ & \\
\hline \multirow[t]{2}{*}{ Participant's Education } & $\begin{array}{l}\text { Primary school and } \\
\text { below }\end{array}$ & $4(3.7 \%)$ & $73(7.4 \%)$ & \multirow[t]{2}{*}{0.15} & $14(7.6 \%)$ & $65(7.0 \%)$ & \multirow[t]{2}{*}{0.75} \\
\hline & Middle school and above & $105(96.3 \%)$ & $909(92.6 \%)$ & & $170(92.4 \%)$ & $869(93.0 \%)$ & \\
\hline \multirow[t]{2}{*}{ Parity } & Nulliparous & $32(29.4 \%)$ & $436(44.4 \%)$ & \multirow[t]{2}{*}{0.003} & $67(36.4 \%)$ & $415(44.4 \%)$ & \multirow[t]{2}{*}{0.05} \\
\hline & Multiparous & $77(70.7 \%)$ & $546(55.6 \%)$ & & $117(63.5 \%)$ & $\begin{array}{l}520 \\
(55.7 \%)\end{array}$ & \\
\hline \multirow[t]{3}{*}{ Family history of diabetes } & None & $74(67.9 \%)$ & $77 I(78.8 \%)$ & \multirow[t]{3}{*}{0.03} & $749(80.3 \%)$ & $122(66.3 \%)$ & \multirow[t]{3}{*}{$<0.001$} \\
\hline & One parent & $30(27.5 \%)$ & $182(18.6 \%)$ & & $162(17.4 \%)$ & $53(28.8 \%)$ & \\
\hline & Both parent & $5(4.6 \%)$ & $26(2.7 \%)$ & & $22(2.4 \%)$ & $9(4.9 \%)$ & \\
\hline $\begin{array}{l}\text { Participant's history of Infertility } \\
\text { treatment }\end{array}$ & Yes & $4(3.7 \%)$ & $9(0.9 \%)$ & $0.03^{\#}$ & $6(3.3 \%)$ & $7(0.8 \%)$ & 0.004 \\
\hline Participant's history of GDM & Yes & $3(2.8 \%)$ & $9(0.9 \%)$ & $0.11^{\#}$ & $I(0.5 \%)$ & $12(1.3 \%)$ & $0.7 I^{\#}$ \\
\hline Participant's history of Hypertension & Yes & $3(2.8 \%)$ & $12(1.2 \%)$ & $0.19^{\#}$ & $14(1.5 \%)$ & $\mathrm{I}(\mathrm{I} .0 \%)$ & $0.49^{\#}$ \\
\hline \multirow[t]{2}{*}{ Metabolic Equivalents (MET) value } & Low & $\mathrm{I}(0.9 \%)$ & $21(2.2 \%)$ & \multirow[t]{2}{*}{$0.72^{\#}$} & $3(1.7 \%)$ & $19(2.1 \%)$ & \multirow[t]{2}{*}{$1.000^{\#}$} \\
\hline & Moderate & $107(99.1 \%)$ & $950(97.8 \%)$ & & I77(98.3\%) & $904(97.9 \%)$ & \\
\hline \multirow[t]{2}{*}{ EPDS score ${ }^{* *}$} & $\leq 13$ & $10 \mathrm{I}(92.7 \%)$ & $897(91.3 \%)$ & \multirow[t]{2}{*}{0.64} & $856(91.6 \%)$ & $168(91.3 \%)$ & \multirow[t]{2}{*}{0.91} \\
\hline & $>13$ & $8(7.3 \%)$ & $85(8.7 \%)$ & & $79(8.4 \%)$ & $16(8.7 \%)$ & \\
\hline Husband's tobacco use & Yes & $51(46.8 \%)$ & $397(41.0 \%)$ & 0.25 & $83(45.4 \%)$ & $378(41 \%)$ & 0.28 \\
\hline \multirow[t]{4}{*}{ Delivery type } & $\begin{array}{l}\text { Spontaneous vaginal } \\
\text { delivery }\end{array}$ & $52(47.7 \%)$ & $516(52.5 \%)$ & \multirow[t]{4}{*}{$0.45^{\#}$} & $78(42 \%)$ & $507(54.2 \%)$ & \multirow[t]{4}{*}{$0.024^{\#}$} \\
\hline & $\begin{array}{l}\text { Emergency caesarean } \\
\text { section }\end{array}$ & $31(28.4 \%)$ & $288(29.3 \%)$ & & $66(36 \%)$ & $259(27.7 \%)$ & \\
\hline & $\begin{array}{l}\text { Elective caesarean } \\
\text { section }\end{array}$ & $26(23.9 \%)$ & $176(17.9 \%)$ & & $40(22 \%)$ & $168(17.9 \%)$ & \\
\hline & Vacuum extraction & 0 & $2(0.2 \%)$ & & 0 & $2(0.2 \%)$ & \\
\hline \multirow[t]{2}{*}{ Health status of the baby } & Healthy & $108(99.1 \%)$ & $974(99.2 \%)$ & $1.000^{\#}$ & $183(100 \%)$ & $928(99.1 \%)$ & $1.000^{\#}$ \\
\hline & Diseased & $\mathrm{I}(0.9 \%)$ & $8(0.8 \%)$ & & $\mathrm{I}(\mathrm{I} .0 \%)$ & $8(0.8 \%)$ & \\
\hline
\end{tabular}


Table 2 (Continued).

\begin{tabular}{|c|c|c|c|c|c|c|c|}
\hline \multicolumn{2}{|l|}{ Characteristics } & \multicolumn{3}{|c|}{ Maternal Obesity Status ${ }^{\mathbf{b}}$} & \multicolumn{3}{|c|}{ GDM Status ${ }^{c}$} \\
\hline & & \multirow{2}{*}{$\begin{array}{l}\begin{array}{l}\text { Yes } \\
(n=109)\end{array} \\
f(\%)\end{array}$} & \multirow{2}{*}{$\begin{array}{l}\begin{array}{l}\text { No } \\
(n=982)\end{array} \\
f(\%)\end{array}$} & \multirow[t]{2}{*}{ p value } & $\begin{array}{l}\text { Yes } \\
(n=\mid 84)\end{array}$ & $\begin{array}{l}\text { No } \\
(n=936)\end{array}$ & \multirow[t]{2}{*}{ p value } \\
\hline & & & & & f (\%) & $f(\%)$ & \\
\hline \multirow[t]{2}{*}{ Sex } & Male & $69(63.3 \%)$ & $486(49.5 \%)$ & \multirow[t]{2}{*}{0.006} & $106(58 \%)$ & $46 I(49.3 \%)$ & \multirow[t]{2}{*}{0.04} \\
\hline & Female & $40(36.7 \%)$ & $496(50.5 \%)$ & & $78(42 \%)$ & $475(50.7 \%)$ & \\
\hline Baby cried soon after delivery & Yes & $106(97.2 \%)$ & $960(97.8 \%)$ & $0.73^{\#}$ & $180(98 \%)$ & $914(97.6 \%)$ & $1.00^{\#}$ \\
\hline Aspiration & Yes & $2(1.8 \%)$ & $22(2.2 \%)$ & $0.60^{\#}$ & $2(1.1 \%)$ & $24(2.6 \%)$ & $0.29^{\#}$ \\
\hline Resuscitation & Yes & $38(34.9 \%)$ & $354(36.0 \%)$ & 0.81 & $67(36 \%)$ & $325(34.7 \%)$ & 0.66 \\
\hline
\end{tabular}

Notes: ${ }^{a}$ Mean \pm standard deviation is mentioned instead of frequency and percentage with an independent sample $t$-test, $\mathrm{p}$ value. ${ }^{\mathrm{b}}$ More than 90 th percentile of sum of skinfold thickness as the obese category. ${ }^{\mathrm{C}}$ Fasting blood sugar (FBS) equal to or more than $92 \mathrm{mg} / \mathrm{dL}$ or $2 \mathrm{hr}$ postprandial blood sugar (PPBS) equal to or more than I $52 \mathrm{mg} /$ $\mathrm{dL}(32)$ as GDM. Bold indicates statistical significance at $5 \%$. \#Fishers exact test $\mathrm{p}$ value. **Scores range from 0 to 30 .

Abbreviation: EPDS, Edinburgh Postnatal Depression Scale to screen for depression.

classification accuracy suggested that model 4 is a better fit to the data than models 1,2 , and 3. Our results indicated that the odds of having adiposity in babies were 1.90 times higher for women with obesity $(95 \%$ CI: $1.16,3.12)$ and 1.99 times higher for women with GDM $(95 \%$ CI: 1.31 , 3.02) adjusting for other confounders.

\section{Mediation Analysis (Table 5)}

Model (a) and (b) from the equations were fitted for mediation analysis. These models were fitted with no interaction and no multicollinearity $(\mathrm{VIF}=1.03)$ between exposure and mediator but adjusted for potential confounders. GDM significantly mediates the relationship between maternal obesity and neonatal adiposity, (natural direct effect $\mathrm{OR}=1.1695 \%$ CI $1.04,1.30$ ) with significant direct effect of maternal obesity (natural direct effect $\mathrm{OR}=1.90$ $95 \%$ CI $1.16,3.10)$ and significant total effect $(\mathrm{OR}=2.20$ $95 \%$ CI $1.35,3.58)$. The results indicate that GDM mediates $25.2 \%$ of the total effect of maternal obesity and neonatal adiposity. With 1000 replications, there were no significant differences in the confidence intervals (Table 5).

\section{Discussion}

We aimed to understand how maternal obesity and GDM during pregnancy are associated with adiposity in the offspring. Our results suggest that both maternal obesity and GDM are independently associated with adiposity in neonates. While neonates born to women with GDM show association with most of the anthropometric markers of adiposity, such association was seen only for birth weight and middle-upper arm circumference in neonates borne to with women with obesity. This finding is corroborated by other studies demonstrating that obesity in offspring is associated with maternal GDM and obesity. ${ }^{47-52}$ Further, results from the regression models showed that GDM is a stronger determinant of adiposity in neonates and mediates the effect of maternal obesity on neonatal adiposity. These results suggest that the risk factors for adiposity in neonates are to be addressed by using a life course perspective.

India is undergoing a rapid epidemiological and demographical transition. ${ }^{53}$ Since GDM affects nearly one in five Indian pregnant women, our current study suggests that it is essential to prioritize GDM screening and management by the policymakers. The Indian national guidelines (2014) recommend GDM screening for all pregnant women during pregnancy. ${ }^{54}$ However, only $44 \%$ of pregnant mothers in public health facilities underwent OGTT as a screening test for GDM. ${ }^{55}$ Besides, the proportion of women who complete the test is also low. The results from public hospitals suggest that women from lower socioeconomic status are equally affected. Therefore, universal screening might be useful in the timely management of GDM and in preventing adverse consequences. ${ }^{56,57}$

Additionally, we also reported that obesity in women is associated with adiposity in neonates. This suggests that early intervention preventing or controlling obesity in young women can end the vicious cycle of obesity across generations. ${ }^{58}$ Interventions aimed at addressing nutritional intake, healthy weight, and physical activity directed at parents can reduce obesity-related health consequences. 
Table 3 Distribution of Neonatal Anthropometric Characteristics Over Obese and GDM Categories

\begin{tabular}{|c|c|c|c|c|c|c|c|}
\hline \multirow[t]{3}{*}{$\begin{array}{l}\text { Neonatal Anthropometric } \\
\text { Characteristics }\end{array}$} & \multirow[t]{3}{*}{ Categories } & \multicolumn{2}{|c|}{$\begin{array}{l}\text { Maternal Obesity } \\
\text { Status }\end{array}$} & \multirow[t]{3}{*}{$\mathrm{p}$ value } & \multicolumn{2}{|c|}{ GDM Status } & \multirow[t]{3}{*}{ p value } \\
\hline & & $\begin{array}{l}\text { Yes } \\
(n=109)\end{array}$ & $\begin{array}{l}\text { No } \\
(n=982)\end{array}$ & & $\begin{array}{l}\text { Yes } \\
(n=184)\end{array}$ & $\begin{array}{l}\text { No } \\
(n=936)\end{array}$ & \\
\hline & & f (\%) & $f(\%)$ & & f (\%) & $f(\%)$ & \\
\hline Birth weight $(\mathrm{kg})$ & $\begin{array}{l}<10 \text { th } \\
10 \text { th }-90 \text { th } \\
>90 \text { th }\end{array}$ & $\begin{array}{l}10(9.2 \%) \\
79(72.5 \%) \\
20(18.3 \%)\end{array}$ & $\begin{array}{l}96(9.8 \%) \\
797(81.2 \%) \\
89(9.1 \%)\end{array}$ & 0.0001 & $\begin{array}{l}\text { II (6.0\%) } \\
\text { I39(75.5\%) } \\
34(18.5 \%)\end{array}$ & $\begin{array}{l}97(10.4 \%) \\
761(81.3 \%) \\
78(8.3 \%)\end{array}$ & 0.01 \\
\hline Crown rump length $(\mathrm{cm})$ & $\begin{array}{l}<10 \text { th } \\
10 \text { th }-90 \text { th } \\
>90 \text { th }\end{array}$ & $\begin{array}{l}10(9.2 \%) \\
88(80.7 \%) \\
11(10.1 \%)\end{array}$ & $\begin{array}{l}99(10.2 \%) \\
779(80.1 \%) \\
95(9.8 \%)\end{array}$ & 0.17 & $\begin{array}{l}14(7.7 \%) \\
139(76.8 \%) \\
28(\mid 5.5 \%)\end{array}$ & $\begin{array}{l}97(10.4 \%) \\
751(80.8 \%) \\
82(8.8 \%)\end{array}$ & 0.14 \\
\hline Length $(\mathrm{cm})$ & $\begin{array}{l}<10 \text { th } \\
10 \text { th }-90 \text { th } \\
>90 \text { th }\end{array}$ & $\begin{array}{l}12(\mid 1.0 \%) \\
81(74.3 \%) \\
16(\mid 4.7 \%)\end{array}$ & $\begin{array}{l}88(9.0 \%) \\
801(81.7 \%) \\
92(9.4 \%)\end{array}$ & 0.33 & $\begin{array}{l}13(7.1 \%) \\
149(81.0 \%) \\
22(12.0 \%)\end{array}$ & $\begin{array}{l}91(9.7 \%) \\
756(80.9 \%) \\
88(9.4 \%)\end{array}$ & 0.25 \\
\hline Head Circumference (cm) & $\begin{array}{l}<10 \text { th } \\
10 \text { th }-90^{\text {th }} \\
>90 \text { th }\end{array}$ & $\begin{array}{l}9(8.3 \%) \\
86(78.0 \% 9) \\
14(\mid 2.8 \%)\end{array}$ & $\begin{array}{l}101(10.3 \%) \\
794(80.9 \%) \\
87(8.9 \%)\end{array}$ & 0.01 & $\begin{array}{l}14(7.6 \%) \\
142(77.2 \%) \\
28(\mid 5.2 \%)\end{array}$ & $\begin{array}{l}98(10.5 \%) \\
762(81.4 \%) \\
76(8.1 \%)\end{array}$ & 0.34 \\
\hline Chest circumference $(\mathrm{cm})$ & $\begin{array}{l}<10 \text { th } \\
10 \text { th }-90 \text { th } \\
>90 \text { th }\end{array}$ & $\begin{array}{l}\text { II(I0.I\%) } \\
84(77.1 \%) \\
14(12.8 \%)\end{array}$ & $\begin{array}{l}93(9.5 \%) \\
807(82.3 \%) \\
81(8.3 \%)\end{array}$ & 0.0001 & $\begin{array}{l}\mid 2(6.5 \%) \\
|4|(76.6 \%) \\
3 \mid(\mid 6.8 \%)\end{array}$ & $\begin{array}{l}99(10.6 \%) \\
768(82.1 \%) \\
68(7.3 \%)\end{array}$ & 0.25 \\
\hline Waist circumference $(\mathrm{cm})$ & $\begin{array}{l}<10 \text { th } \\
10 \text { th }-90^{\text {th }} \\
>90 \text { th }\end{array}$ & $\begin{array}{l}\mathrm{II}(10.1 \%) \\
88(80.7 \%) \\
10(9.2 \%)\end{array}$ & $\begin{array}{l}98(10.0 \%) \\
801(81.6 \%) \\
83(8.5 \%)\end{array}$ & 0.10 & $\begin{array}{l}12(6.5 \%) \\
15 \mid(82 . \mid \%) \\
21(\mid 1.4 \%)\end{array}$ & $\begin{array}{l}100(10.7 \%) \\
760(81.2 \%) \\
76(8.1 \%)\end{array}$ & 0.91 \\
\hline Hip Circumference $(\mathrm{cm})$ & $\begin{array}{l}<10 \text { th } \\
10 \text { th }-90^{\text {th }} \\
>90 \text { th }\end{array}$ & $\begin{array}{l}10(9.2 \%) \\
84(77.1 \%) \\
15(13.8 \%)\end{array}$ & $\begin{array}{l}84(8.6 \%) \\
811(82.6 \%) \\
87(8.9 \%)\end{array}$ & 0.02 & $\begin{array}{l}8(4.3 \%) \\
152(82.6 \%) \\
24(13.0 \%)\end{array}$ & $\begin{array}{l}89(9.5 \%) \\
767(81.9 \%) \\
80(8.5 \%)\end{array}$ & 0.23 \\
\hline Mid upper arm circumference $(\mathrm{cm})$ & $\begin{array}{l}<10 \text { th } \\
10 \text { th }-90^{\text {th }} \\
>90 \text { th }\end{array}$ & $\begin{array}{l}\mathrm{II}(10.1 \%) \\
78(71.6 \%) \\
20(18.3 \%)\end{array}$ & $\begin{array}{l}104(10.6 \%) \\
790(80.4 \%) \\
88(9.0 \%)\end{array}$ & 0.0003 & $\begin{array}{l}\text { II (6\%) } \\
142(77.2 \%) \\
31(16.8 \%)\end{array}$ & $\begin{array}{l}109(11.6 \%) \\
749(80.0 \%) \\
78(8.3 \%)\end{array}$ & 0.01 \\
\hline Sum of skinfold thickness (mm) & $\begin{array}{l}<10^{\text {th }} \\
10 \text { th }-85^{\text {th }} \\
>85^{\text {th }}\end{array}$ & $\begin{array}{l}4(3.7 \%) \\
77(70.6 \%) \\
28(25.7 \%)\end{array}$ & $\begin{array}{l}105(10.7 \%) \\
744(75.8 \%) \\
133(13.5 \%)\end{array}$ & 0.001 & $\begin{array}{l}15(8.2 \%) \\
125(67.9 \%) \\
44(23.9 \%)\end{array}$ & $\begin{array}{l}97(10.4 \%) \\
720(76.9 \%) \\
119(12.7 \%)\end{array}$ & $<0.001$ \\
\hline
\end{tabular}

Note: Bold indicates statistical significance at $5 \%$.

We also reported that instead of birth weight, the skinfold thickness of neonates is a reliable marker of adiposity in identifying adverse consequences in the offspring of women with obesity and GDM. The relatively high cost of the calipers and the need for rigorous training and validation of the measurements by research staff makes it tough for scaling up in public hospitals. Our results indicate that a similar positive association is seen with the middle-upper arm circumference for adiposity in neonates. These indirect methods of measurements can be used for identifying and tracking adiposity in neonates, especially in resource-scarce settings, thus ideal for public hospitals. Previous studies have shown the measurements of MUAC, and CC as measures of adiposity are not only comparable to dual-energy X-ray (DXA) or underwater weighing but also costeffective and applicable for larger populations. ${ }^{59-66}$

Further, we found that GDM mediates $25.2 \%$ of the association between obesity in women with neonatal adiposity. Future studies can inform regarding the exact biological nature of this mediation mechanism to uncover the causal path between obesity in mother and neonatal adiposity. Maternal obesity has both a direct and indirect effect on infant adiposity. We show that the clustering of risk factors of obesity and GDM predisposes infants to NCDs 
Table 4 Logistic Regression Models: Effect of GDM and Obesity Adjusted for Potential Confounders on Neonatal Adiposity

\begin{tabular}{|c|c|c|c|c|c|c|}
\hline \multicolumn{2}{|l|}{ Variables } & \multicolumn{5}{|c|}{ Sum of Skinfold Thickness } \\
\hline & & \multirow{2}{*}{$\begin{array}{l}\text { Univariate } \\
\begin{array}{l}\text { Unadjusted OR } \\
(95 \% \mathrm{Cl})\end{array}\end{array}$} & $\begin{array}{l}\text { Model I } \\
\text { Including } \\
\text { Obesity }\end{array}$ & $\begin{array}{l}\text { Model } 2 \\
\text { Including } \\
\text { GDM }\end{array}$ & \multirow[t]{2}{*}{$\begin{array}{l}\text { Model } 3 \text { Obesity with } \\
\text { GDM and Interaction }\end{array}$} & \multirow[t]{2}{*}{$\begin{array}{l}\text { Model } 4 \\
\text { Obesity, GDM } \\
\text { Without Interaction }\end{array}$} \\
\hline & & & Adjusted OR (95 & $\% \mathbf{C l})$ & & \\
\hline \multirow{2}{*}{$\begin{array}{l}\text { Participant's obesity } \\
\text { status }\end{array}$} & Yes & $2.21(1.38,3.52)$ & $2.18(1.35,3.54)$ & - & $1.80(0.95,3.40)$ & $1.90(1.16,3.12)$ \\
\hline & No & $\mathbf{I}$ & I & - & I & $\mathbf{I}$ \\
\hline \multirow[t]{2}{*}{$\begin{array}{l}\text { Current GDM status } \\
\text { during assessment }\end{array}$} & Yes & $2.16(1.46,3.18)$ & - & $\begin{array}{l}2.18(1.45 \\
3.28)\end{array}$ & $1.93(1.21,3.10)$ & $1.99(1.31,3.02)$ \\
\hline & No & $\mathbf{I}$ & - & I & I & $\mathbf{I}$ \\
\hline \multirow[t]{3}{*}{ Religion } & Hinduism & $1.02(0.73,1.43)$ & $1.07(0.73,1.58)$ & $\mathrm{I} .03(0.70, \mathrm{I} .5 \mathrm{I})$ & $1.07(0.73,1.58)$ & $1.08(0.73,1.58)$ \\
\hline & Christianity & $1.35(0.57,3.17)$ & $1.45(0.60,3.52)$ & $1.50(0.62,3.64)$ & $\mathrm{I} .52(0.63,3.7 \mathrm{I})$ & $1.52(0.63,3.70)$ \\
\hline & Islam & 1 & I & I & I & I \\
\hline \multirow[t]{2}{*}{ MET values } & Low & 1 & 1 & 1 & 1 & I \\
\hline & Moderate & $1.09(0.32,3.73)$ & $3.01(0.40,22.87)$ & $\begin{array}{l}3.17(0.4 I \\
24.32)\end{array}$ & $3.13(0.41,24.09)$ & $3.10(0.40,23.88)$ \\
\hline \multirow{2}{*}{$\begin{array}{l}\text { Participant's history } \\
\text { of diabetes }\end{array}$} & Yes & $1.78(0.48,6.52)$ & $\mathrm{I} .65(0.4 \mathrm{I}, 6.63)$ & $2.07(0.52,8.26)$ & $1.81(0.44,7.45)$ & $1.8 \mathrm{I}(0.44,7.46)$ \\
\hline & No & 1 & 1 & I & I & I \\
\hline \multirow[t]{2}{*}{ Parity } & Nulliparous & 1 & 1 & 1 & 1 & I \\
\hline & Multiparous & $1.17(0.83,1.64)$ & $1.19(0.81,1.74)$ & $1.22(0.83,1.78)$ & $1.19(0.81,1.75)$ & $1.19(0.8 \mathrm{I}, 1.75)$ \\
\hline \multirow{3}{*}{$\begin{array}{l}\text { Family history of } \\
\text { diabetes }\end{array}$} & None & 1 & I & I & I & I \\
\hline & One parent & $1.10(0.73,1.67)$ & $1.09(0.70,1.68)$ & $1.04(0.67,1.61)$ & $1.03(0.66,1.61)$ & $1.03(0.66,1.60)$ \\
\hline & Both parent & $1.77(0.75,4.20)$ & $1.87(0.77,4.58)$ & I.75(0.7I, 4.30) & $1.68(0.67,4.18)$ & $1.69(0.68,4.20)$ \\
\hline \multirow{2}{*}{$\begin{array}{l}\text { Husband's alcohol } \\
\text { consumption status }\end{array}$} & Yes & $1.33(0.85,2.08)$ & $\mathrm{I} .4 \mathrm{I}(0.87,2.30)$ & $1.40(0.86,2.29)$ & $1.43(0.87,2.33)$ & $\mathrm{I} .42(0.87,2.33)$ \\
\hline & No & 1 & 1 & I & 1 & I \\
\hline \multicolumn{2}{|l|}{ Maternal age } & $1.00(0.96,1.04)$ & $0.99(0.94,1.04)$ & $0.98(0.94,1.03)$ & $0.98(0.93,1.03)$ & $0.98(0.93,1.03)$ \\
\hline \multicolumn{2}{|l|}{ Husband's income } & $1.00(1.00,1.00)$ & $1.00(1.00,1.00)$ & $1.00(1.00,1.00)$ & $1.00(1.00,1.00)$ & $1.00(1.00,1.00)$ \\
\hline \multicolumn{2}{|l|}{ Participant's height } & $1.01(0.98,1.04)$ & $1.02(0.99,1.05)$ & $1.02(0.99,1.05)$ & $1.02(0.99,1.05)$ & $1.02(0.99,1.05)$ \\
\hline \multicolumn{5}{|c|}{ Interaction (Obesity $\times$ GDM) } & $P$ value $=0.78$ & - \\
\hline \multicolumn{3}{|l|}{ 2log likelihood } & 868.65 & 865.88 & 859.77 & 857.77 \\
\hline \multicolumn{3}{|l|}{ Nagelkerke R Square } & 0.032 & 0.038 & 0.048 & 0.048 \\
\hline \multicolumn{3}{|c|}{ Hosmer \& Lemeshow test } & $\chi^{2}=4.82, p=0.77$ & $\begin{array}{l}\chi^{2}=4.89 \\
p=0.77\end{array}$ & $\chi^{2}=5.06, p=0.75$ & $\chi^{2}=5.06, p=0.77$ \\
\hline \multicolumn{3}{|l|}{ Classification accuracy } & $85.2 \%$ & $85.3 \%$ & $85.3 \%$ & $85.3 \%$ \\
\hline
\end{tabular}

Notes: Clinically relevant confounders have been included in the model thought the p value is not less than 0.20 . Model I- Maternal obesity, maternal age, maternal height, Religion, MET values, Husband's income, Diabetes history in family, Parity, Husband's alcohol consumption status. Model 2- GDM, maternal age, maternal height, Religion, MET values, Husband's income, Diabetes history in family, Parity, Husband's alcohol consumption status. Model 3- Maternal obesity, GDM, interaction (Obesity × GDM), Age, Height, Religion, MET values, Husband's income, Diabetes history in family, Parity, Husband's alcohol consumption status. Model 4 -Maternal obesity, GDM, maternal age, maternal height, Religion, MET values, Husband's income, Diabetes history in family, Parity, Husbands alcohol consumption status. Bold indicates statistical significance at $5 \%$.

Abbreviations: OR, Odds ratio; $\mathrm{Cl}$, confidence interval. 
Table 5 Results of Mediation Analysis Adjusted for Potential Confounders

\begin{tabular}{|l|l|l|}
\hline & OR $(95 \%$ Cl) & p value \\
\hline Natural direct effect & $1.90(1.16,3.10)$ & $0.011^{*}$ \\
Natural Indirect effect & $1.16(1.04,1.30)$ & $0.008^{*}$ \\
Marginal total effect & $2.20(1.35,3.58)$ & $0.001^{*}$ \\
Proportion mediated & 0.252 & - \\
\hline
\end{tabular}

Note: *Indicates statistical significance at $5 \%$.

Abbreviation: $\mathrm{Cl}$, confidence interval.

later in life in India. This concurs with earlier studies in the field, showing that maternal obesity is reflective of overall lifestyle and genetics, ${ }^{67,68}$ whereas the effects of GDM might be transient. Our results indicate that children born to mothers who have obesity and GDM as a clustered condition are programmed to a different growth trajectory in early life. Recent evidence suggests that children of obese mothers have increased BMI, blood pressure, and carotid intima-media-adventitia thickness. ${ }^{69}$ Our results indicate that there is a transgenerational effect of maternal obesity and GDM in infants.

The strengths of our study are that it is by far the largest pregnancy cohort in the public-sector health facilities in India to assess the relationship between maternal hyperglycemia and neonatal adiposity as a marker for later chronic conditions. We established the cohort since April 2016, and have included an almost equal proportion of minority groups that mainly belong to the vulnerable sections of the society. Our research staff was well trained, the equipment is well-calibrated, and rigorous quality control measures are strictly followed, complying with the standard operating procedures. Our findings inform policy formulation for scaling up screening for GDM and management in all the public health facilities. The main limitation is the unavailability of the pre-pregnancy BMI of the enrolled participants. This reduced our ability to compare gestational weight gain and its influence on neonatal adiposity. However, since our inclusion criteria include pregnant women that had completed more than 14 weeks of gestational age, the weight before conception was out of the scope of our study. No currently available method to carry out sensitivity analysis was possible since the outcome, exposure, and the mediator variable are dichotomous.

\section{Conclusion}

Our study showed that maternal obesity and GDM are independently related to neonatal adiposity in women belonging to low and middle-income urban India. Also, we found that GDM is a stronger determinant of neonatal adiposity compared to maternal obesity. Since obesity development is influenced in utero, screening, and management of obesity and GDM can limit the future epidemics of childhood obesity.

\section{Data Sharing Statement}

To discuss our data sharing policy, please contact Giridhara R. Babu at giridhar@iiphh.org.

\section{Acknowledgments}

We sincerely thank all the medical doctors and staff from the study centers in Bangalore for their continuous support in the ongoing study. Our sincere thanks to Dr. Suresh Shapeti and Mr. T.S. Ramesh for facilitating the administrative support and coordination. We thank Mr. Gurulingaiah, Ms. Maithili Karthik, Mr. Kiran Kumar HN, Ms. Keerthi Deshpande, Ms. Sindhu Gowda, Ms. Meena, and others for their support in carrying out research activities in the field. We also thank all accredited social health activists for mobilizing participants at the community level. We thank all participants for their effort to enroll and continuous participation in the ongoing cohort.

\section{Author Contributions}

All authors made substantial contributions to conception and design, acquisition of data, or analysis and interpretation of data; took part in drafting the article or revising it critically for important intellectual content; gave final approval of the version to be published; and agree to be accountable for all aspects of the work.

\section{Funding}

The MAASTHI cohort is funded by an Intermediate Fellowship by the Wellcome Trust DBT India Alliance (Clinical and Public Health research fellowship) to Giridhara R Babu; grant number: IA/CPHI/14/1/501499. The funding agency had no role in the design and conduct of the study; collection, management, analysis, and interpretation of the data; preparation, review, or approval of the manuscript; or decision to submit the manuscript for publication.

\section{Disclosure}

The authors declare that they have no competing interests. 


\section{References}

1. Lynch C, Sexton D, Hession M, Morrison JJ. Obesity and mode of delivery in primigravid and multigravid women. Am J Perinatol. 2008;25(3):163-167. doi:10.1055/s-2008-1061496

2. De Boo HA, Harding JE. The developmental origins of adult disease (Barker) hypothesis. Aust N Zeal J Obstet Gynaecol. 2006;46 (1):4-14. doi:10.1111/j.1479-828X.2006.00506.x

3. Chen $\mathrm{C}, \mathrm{Xu} \mathrm{X}$, Yan Y. Estimated global overweight and obesity burden in pregnant women based on panel data model. PLOS ONE. 2018;13(8):e0202183. doi:10.1371/journal.pone.0202183

4. World Health Organisation. WHO Global Infobase; 2016.

5. Whitaker RC. Predicting preschooler obesity at birth: the role of maternal obesity in early pregnancy. Pediatrics. 2004;114(1):e29e36. doi:10.1542/peds.114.1.e29

6. Ehrenberg HM, Mercer BM, Catalano PM. The influence of obesity and diabetes on the prevalence of macrosomia. Am J Obstet Gynecol. 2004;191(3):964-968. doi:10.1016/j.ajog.2004.05.052

7. Chu SY, Kim SY, Lau J, et al. Maternal obesity and risk of stillbirth: a metaanalysis. Am J Obstet Gynecol. 2007;197(3):223-228. doi:10.1016/j.ajog.2007.03.027

8. Ananth CV, Wen SW, editors. Trends in fetal growth among singleton gestations in the United States and Canada, 1985 through 1998. In: Seminars in perinatology; 2002: Elsevier. doi:10.1053/sper.2002.34772

9. Ørskou J, Kesmodel U, Henriksen TB, Secher NJ. An increasing proportion of infants weigh more than 4000 grams at birth. Acta Obstet Gynecol Scand. 2001;80(10):931-936. doi:10.1034/j.16000412.2001.801010.x

10. Surkan PJ, Hsieh -C-C, Johansson AL, Dickman PW, Cnattingius S. Reasons for increasing trends in large for gestational age births. Obstet Gynecol. 2004;104(4):720-726. doi:10.1097/01. AOG.0000141442.59573.cd

11. Catalano P, Ehrenberg H. The short-and long-term implications of maternal obesity on the mother and her offspring. BJOG. 2006;113 (10):1126-1133. doi:10.1111/j.1471-0528.2006.00989.x

12. Radaelli T, Varastehpour A, Catalano P, Hauguel-de Mouzon S. Gestational diabetes induces placental genes for chronic stress and inflammatory pathways. Diabetes. 2003;52(12):2951-2958. doi:10.2337/diabetes.52.12.2951

13. Federation ID. The IDF approach for care and management of Gestational Diabetes Mellitus Report; 2017.

14. Miao M, Dai M, Zhang Y, Sun F, Guo X, Sun G. Influence of maternal overweight, obesity and gestational weight gain on the perinatal outcomes in women with gestational diabetes mellitus. Sci Rep. 2017;7(1):305. doi:10.1038/s41598-017-00441-z

15. McGuane JT, Grlj L, Peek MJ. Obesity, gestational diabetes and macrosomia are associated with increasing rates of early-term induction of labour at The Canberra Hospital. Aust $N$ Zeal J Obstet Gynaecol. 2019;59(2):215-220. doi:10.1111/ajo.2019.59.issue-2

16. Hedderson MM, Ferrara A, Sacks DA. Gestational diabetes mellitus and lesser degrees of pregnancy hyperglycemia: association with increased risk of spontaneous preterm birth. Obstet Gynecol. 2003;102(4):850-856.

17. Yogev Y, Most O, Langer O. Gestational diabetes mellitus: is their a risk for perinatal mortality? Am J Obstet Gynecol. 2004;191(6):S51.

18. Nohr EA, Bech BH, Davies MJ, Frydenberg M, Henriksen TB, Olsen J. Prepregnancy obesity and fetal death: a study within the Danish National Birth Cohort. Obstet Gynecol. 2005;106 (2):250-259. doi:10.1097/01.AOG.0000172422.81496.57

19. Lauszus F, Paludan J, Klebe J. Birthweight in women with potential gestational diabetes mellitus-an effect of obesity rather than glucose intolerance? Acta Obstet Gynecol Scand. 1999;78(6):520-525. doi:10.1080/j.1600-0412.1999.780608.x

20. Hod M, Rabinerson D, Kaplan B, et al. Perinatal complications following gestational diabetes mellitus how 'sweet'is ill? Acta Obstet Gynecol Scand. 1996;75(9):809-815. doi:10.3109/00016349609054708
21. Chu SY, Callaghan WM, Kim SY, et al. Maternal obesity and risk of gestational diabetes mellitus. Diabetes Care. 2007;30(8):2070-2076. doi: $10.2337 / \mathrm{dc} 06-2559 \mathrm{a}$

22. Catalano PM, Thomas A, Huston-Presley L, Amini SB. Increased fetal adiposity: a very sensitive marker of abnormal in utero development. Am J Obstet Gynecol. 2003;189(6):1698-1704. doi:10.1016/S0002-9378(03)00828-7

23. Gillman MW, Rifas-Shiman S, Berkey CS, Field AE, Colditz GA. Maternal gestational diabetes, birth weight, and adolescent obesity. Pediatrics. 2003;111(3):e221-e6. doi:10.1542/peds.111.3. e221

24. Sewell MF, Huston-Presley L, Super DM, Catalano P. Increased neonatal fat mass, not lean body mass, is associated with maternal obesity. Am J Obstet Gynecol. 2006;195(4):1100-1103. doi:10.1016/ j.ajog.2006.06.014

25. Hull HR, Dinger MK, Knehans AW, Thompson DM, Fields DA. Impact of maternal body mass index on neonate birthweight and body composition. Am J Obstet Gynecol. 2008;198(4):416. e1-. e6. doi:10.1016/j.ajog.2007.10.796

26. Poprzeczny AJ, Louise J, Deussen AR, Dodd JM. The mediating effects of gestational diabetes on fetal growth and adiposity in women who are overweight and obese: secondary analysis of the LIMIT randomised trial. BJOG. 2018;125(12):1558-1566. doi:10.1111/bjo.2018.125.issue12

27. Catalano PM, McIntyre HD, Cruickshank JK, et al. The hyperglycemia and adverse pregnancy outcome study: associations of GDM and obesity with pregnancy outcomes. Diabetes Care. 2012;35 (4):780-786. doi: $10.2337 / \mathrm{dc} 11-1790$

28. Hedderson MM, Williams MA, Holt VL, Weiss NS, Ferrara A. Body mass index and weight gain prior to pregnancy and risk of gestational diabetes mellitus. Am J Obstet Gynecol. 2008;198(4):409e1-e7. doi:10.1016/j.ajog.2007.09.028

29. Sciences IIoP. National Family Health Survey (NFHS-4) 2015-16 India; 2017.

30. Babu GR, Murthy G, Deepa R, et al. Maternal antecedents of adiposity and studying the transgenerational role of hyperglycemia and insulin (MAASTHI): a prospective cohort study. BMC Pregnancy Childbirth. 2016;16(1):311. doi:10.1186/s12884-016$1088-4$

31. Bharathi AV, Kuriyan R, Kurpad AV, et al. Assessment of physical activity using accelerometry, an activity diary, the heart rate method and the Indian migration study questionnaire in south Indian adults. Public Health Nutr. 2010;13(1):47-53. doi:10.1017/S13689800090 05850

32. Pastakia SD, Njuguna B, Ajwang'Onyango B, et al. Prevalence of gestational diabetes mellitus based on various screening strategies in western Kenya: a prospective comparison of point of care diagnostic methods. BMC Pregnancy Childbirth. 2017;17(1):226. doi:10.1186/ s12884-017-1415-4

33. Diabetes IAo, Panel PSGC. International association of diabetes and pregnancy study groups recommendations on the diagnosis and classification of hyperglycemia in pregnancy. Diabetes Care. 2010;33 (3):676-682.

34. Kumar VS, Jeyaseelan L, Sebastian T, Regi A, Mathew J, Jose R. New birth weight reference standards customised to birth order and sex of babies from South India. BMC Pregnancy Childbirth. 2013;13 (1):38. doi:10.1186/1471-2393-13-38

35. Babu GR, Murthy G, Reddy Y, et al. Small for gestational age babies and depressive symptoms of mothers during pregnancy: results from a birth cohort in India. Wellcome Open Res. 2019;3.

36. Cypryk K, Szymczak W, Czupryniak L, Sobczak M, Lewiński A. Gestational diabetes mellitus-an analysis of risk factors. Endokrynol Pol. 2008;59(5):393-397.

37. Kale SD, Kulkarni S, Lubree H, et al. Characteristics of gestational diabetic mothers and their babies in an Indian diabetes clinic. JAPI. 2005;53. 
38. Arora GP, Thaman RG, Prasad RB, et al. Prevalence and risk factors of gestational diabetes in Punjab, North India: results from a population screening program. Eur J Endocrinol. 2015;173 (2):257-267. doi:10.1530/EJE-14-0428

39. Gao X, Yan Y, Xiang S, et al. The mutual effect of pre-pregnancy body mass index, waist circumference and gestational weight gain on obesity-related adverse pregnancy outcomes: a birth cohort study. PLoS ONE. 2017;12(6):e0177418. doi:10.1371/journal.pone.0177418

40. Harrod CS, Chasan-Taber L, Reynolds RM, et al. Physical activity in pregnancy and neonatal body composition: the Healthy Start study. Obstet Gynecol. 2014;124(2 0 1):257. doi:10.1097/AOG.0000000000000373

41. Dye TD, Knox KL, Artal R, Aubry RH, Wojtowycz MA. Physical activity, obesity, and diabetes in pregnancy. Am J Epidemiol. 1997;146(11):961-965. doi:10.1093/oxfordjournals.aje.a009223

42. Vittinghoff E, Sen Ś, McCulloch C. Sample size calculations for evaluating mediation. Stat Med. 2009;28(4):541-557. doi:10.1002/ $\operatorname{sim} .3491$

43. Midi H, Sarkar SK, Rana S. Collinearity diagnostics of binary logistic regression model. J Interdiscipl Mathematics. 2010;13(3):25 3-267. doi:10.1080/09720502.2010.10700699

44. VanderWeele TJ, Vansteelandt S. Odds ratios for mediation analysis for a dichotomous outcome. Am J Epidemiol. 2010;172(12):13 39-1348. doi:10.1093/aje/kwq332

45. Emsley R, Liu H PARAMED: Stata module to perform causal mediation analysis using parametric regression models; 2013.

46. Baron RM, Kenny DA. The moderator-mediator variable distinction in social psychological research: conceptual, strategic, and statistical considerations. J Pers Soc Psychol. 1986;51(6):1173. doi:10.1037/ 0022-3514.51.6.1173

47. Pettitt DJ, Baird HR, Aleck KA, Bennett PH, Knowler WC. Excessive obesity in offspring of Pima Indian women with diabetes during pregnancy. $N$ Engl J Med. 1983;308(5):242-245. doi:10.1056/ NEJM198302033080502

48. Silverman BL, Rizzo T, Green OC, et al. Long-term prospective evaluation of offspring of diabetic mothers. Diabetes. 1991;40 (Supplement 2):121-125. doi:10.2337/diab.40.2.S121

49. Baker PR II, Shapiro AL, Becky A, et al. Maternal obesity and increased neonatal adiposity correspond with altered infant mesenchymal stem cell metabolism. JCI Insight. 2017;2:21. doi:10.1172/jci. insight. 94200

50. Starling AP, Brinton JT, Glueck DH, et al. Associations of maternal BMI and gestational weight gain with neonatal adiposity in the Healthy Start study. Am J Clin Nutr. 2014;101(2):302-309. doi:10.3945/ajen.114.094946

51. Fraser A, Lawlor DA. Long-term health outcomes in offspring born to women with diabetes in pregnancy. Curr Diab Rep. 2014;14 (5):489. doi:10.1007/s11892-014-0489-x

52. Waterland RA, Garza C. Potential mechanisms of metabolic imprinting that lead to chronic disease. Am J Clin Nutr. 1999;69(2):179-197. doi:10.1093/ajcn/69.2.179

53. Yadav S, Arokiasamy P. Understanding epidemiological transition in India. Glob Health Action. 2014;7(1):23248. doi:10.3402/gha.v7.23248

54. Welfare. MHDMoHaF. Government of India National Guidelines for Diagnosis \& Management of Gestational Diabetes Mellitus; 2014.

55. Babu GR, Tejaswi B, Kalavathi M, et al. Assessment of screening practices for gestational hyperglycaemia in public health facilities: a descriptive study in Bangalore, India. $J$ Public Health Res. 2015;4:1. doi:10.4081/jphr.2015.448
56. Crowther CA, Hiller JE, Moss JR, McPhee AJ, Jeffries WS, Robinson JS. Effect of treatment of gestational diabetes mellitus on pregnancy outcomes. $N$ Engl J Med. 2005;352(24):2477-2486. doi:10.1056/NEJMoa042973

57. Bhavadharini B, Mahalakshmi MM, Maheswari K, et al. Use of capillary blood glucose for screening for gestational diabetes mellitus in resource-constrained settings. Acta Diabetol. 2016;53(1):91-97. doi:10.1007/s00592-015-0761-9

58. Catalano PM. Obesity and Pregnancy-The Propagation of a Viscous Cycle? Oxford University Press; 2003.

59. Arisoy AE, Sarman G. Chest and mid-arm circumferences: identification of low birth weight newborns in Turkey. J Trop Pediatr. 1995;41(1):34-37. doi:10.1093/tropej/41.1.34

60. Thi HN, Khanh DKT, Thu HLT, Thomas EG, Lee KJ, Russell FM. Foot length, chest circumference, and mid upper arm circumference are good predictors of low birth weight and prematurity in ethnic minority newborns in Vietnam: a hospital-based observational study. PLoS ONE. 2015;10(11):e0142420. doi:10.1371/journal.pone.014 2420

61. Goto E. Meta-analysis: identification of low birthweight by other anthropometric measurements at birth in developing countries. J Epidemiol. 2011;21(5):354-362. doi:10.2188/jea.JE20100182

62. Chaput JP, Katzmarzyk P, Barnes J, et al. Mid-upper arm circumference as a screening tool for identifying children with obesity: a 12 country study. Pediatr Obes. 2017;12(6):439-445. doi:10.1111/ijpo. 12162

63. Craig E, Bland R, Ndirangu J, Reilly J. Use of mid-upper arm circumference for determining overweight and overfatness in children and adolescents. Arch Dis Child. 2014;99(8):763-766. doi:10.11 36/archdischild-2013-305137

64. Lu Q, Wang R, Lou D-H, Ma C-M, Liu X-L, Yin F-Z. Mid-upperarm circumference and arm-to-height ratio in evaluation of overweight and obesity in Han children. Pediat Neonatol. 2014;55 (1):14-19. doi:10.1016/j.pedneo.2013.05.004

65. Jaiswal M, Bansal R, Agarwal A. Role of mid-upper arm circumference for determining overweight and obesity in children and adolescents. J Clin Diagn Res. 2017;11(8):SC05. doi:10.7860/ JCDR/2017/24731.9963

66. Mazıcıoğlu MM, Hatipoğlu N, Öztürk A, Çiçek B, Üstünbaş HB, Kurtoğlu S. Waist circumference and mid- upper arm circumference in evaluation of obesity in children aged between 6 and 17 years. J Clin Res Pediatr Endocrinol. 2010;2(4):144. doi:10.4274/jcrpe. v2i4.144

67. Tan HC, Roberts J, Catov J, Krishnamurthy R, Shypailo R, Bacha F. Mother's pre-pregnancy BMI is an important determinant of adverse cardiometabolic risk in childhood. Pediatr Diabetes. 2015;16 (6):419-426. doi:10.1111/pedi.2015.16.issue-6

68. Ferreira DLS, Williams DM, Kangas AJ, et al. Association of pre-pregnancy body mass index with offspring metabolic profile: analyses of 3 European prospective birth cohorts. PLoS Med. 2017;14(8):e1002376. doi:10.1371/journal.pmed.1002376

69. Sundholm JK, Litwin L, Rönö K, Koivusalo SB, Eriksson JG, Sarkola T. Maternal obesity and gestational diabetes: impact on arterial wall layer thickness and stiffness in early childhood-RADIEL study six-year follow-up. Atherosclerosis. 2019;284:237-244. doi:10.1016/j.atherosclerosis.2019.01.037 


\section{Publish your work in this journal}

Clinical Epidemiology is an international, peer-reviewed, open access, online journal focusing on disease and drug epidemiology, identification of risk factors and screening procedures to develop optimal preventative initiatives and programs. Specific topics include: diagnosis, prognosis, treatment, screening, prevention, risk factor modification, systematic reviews, risk \& safety of medical interventions, epidemiology \& biostatistical methods, and evaluation of guidelines, translational medicine, health policies \& economic evaluations. The manuscript management system is completely online and includes a very quick and fair peer-review system, which is all easy to use. 